\title{
Quantification of Internal Filtration in Hollow Fiber Hemodialyzers with Medium Cut-Off Membrane
}

\author{
Anna Lorenzin $^{\mathrm{a}}$ Mauro Neri $^{\mathrm{a}}$ Andrea Lupi $^{\mathrm{b}}$ Martina Todesco ${ }^{\mathrm{a}}$ \\ Monica Santimaria ${ }^{b}$ Alberta Alghisi $^{c}$ Alessandra Brendolan ${ }^{d}$ \\ Claudio Ronco ${ }^{\mathrm{a}-\mathrm{d}}$ \\ ${ }^{a}$ International Renal Research Institute of Vicenza, Vicenza, Italy; ${ }^{b}$ Department of Nuclear medicine, \\ San Bortolo Hospital, aULSS8 Berica, Vicenza, Italy; ${ }^{\circ}$ Department of Transfusion Medicine, San Bortolo \\ Hospital, aULSS8 Berica, Vicenza, Italy; ${ }^{\mathrm{d}}$ Department of Nephrology Dialysis and Transplantation, \\ St. Bortolo Hospital, aULSS8 Berica, Vicenza, Italy
}

\section{Keywords}

Expanded hemodialysis · Medium cut-off · Dialysis membrane $\cdot$ Internal filtration $\cdot$ Nuclear imaging

\section{Abstract}

Background: Inadequate removal of molecules between 5 and $50 \mathrm{KDa}$ may cause long-term complication in chronic hemodialysis. Medium cut-off (MCO) is a new class of membranes with enhanced sieving properties and negligible albumin loss. MCO membrane makes it possible to perform expanded hemodialysis (HDx), a technique based on high internal filtration (IF).The present study is designed to quantify IF in 2 MCO dialyzers (Theranova 400 and 500, Baxter, Deerfield, USA) using a nuclear imaging technique previously validated. Methods: Blood and dialysate compartment pressure drop along with transmembrane pressure; they were measured in a closed in vitro circuit with human blood (blood flow $\left[\mathrm{Q}_{B}\right]=300$ and $400 \mathrm{~mL} / \mathrm{min}$; dialysate flow $500 \mathrm{~mL} / \mathrm{min}$; net ultrafiltration rate $0 \mathrm{~mL} / \mathrm{min}$ ). A non-diffusible marker molecule (albumin macro-aggregates labeled with ${ }^{99} \mathrm{Tc}$ metastable) was injected in the blood compartment and nuclear emission was recorded by a gamma cam- era. Relative variations in the concentration of the marker molecule along the length of the filter were used to calculate local cross filtration. Results: Based on marker concentration profiles, IF was estimated. For Theranova 400, IF were 29.7 and $41.6 \mathrm{~mL} / \mathrm{min}$ for $\mathrm{Q}_{B}$ of 300 and $400 \mathrm{~mL} / \mathrm{min}$. For Theranova 500 , IF were 31.6 and $53.1 \mathrm{~mL} / \mathrm{min}$ for $Q_{B}$ of 300 and $400 \mathrm{~mL} / \mathrm{min}$ respectively. Conclusions: $\mathrm{MCO}$ membrane provides significant amounts of IF due to the particular combination between hydraulic permeability of the membrane and reduced inner diameter of the fibers. High IF combined with enhanced sieving profile of MCO membrane leads to improved removal of a wider spectrum of uremia retention molecules in $\mathrm{HDx}$, without requiring complex equipment.

(c) 2019 The Author(s)
Published by S. Karger AG, Basel

\section{Introduction}

Uremic syndrome is characterized by a progressive accumulation of molecules that are not adequately excreted in chronic kidney disease (CKD) [1]. In end-stage kidney disease (ESKD), the replacement of renal function by dialysis is also incomplete, since removal of such molecules

\section{KARGER}

E-Mail karger@karger.com www.karger.com/bpu (c) 2019 The Author(s) Published by S. Karger AG, Basel

Karger

Open access

This article is licensed under the Creative Commons AttributionNonCommercial-NoDerivatives 4.0 International License (CC BYNC-ND) (http://www.karger.com/Services/OpenAccessLicense) Usage and distribution for commercial purposes as well as any distribution of modified material requires written permission.
Anna Lorenzin

International Renal Research Institute of Vicenza

San Bortolo Hospital, Viale Rodolfi, 37

IT-36100 Vicenza (Italy)

E-Mail lorenzin.anna@gmail.com 
Table 1. Characteristics of the studied hemodialyzers

\begin{tabular}{|c|c|c|c|c|c|c|c|}
\hline Hemodialyzer & $\begin{array}{l}\text { Fiber inner } \\
\text { diameter, } \mu \mathrm{m}\end{array}$ & $\begin{array}{l}\text { Fiber effective } \\
\text { length, } \mathrm{mm}\end{array}$ & $\begin{array}{l}\text { Number } \\
\text { of fibers }\end{array}$ & $\begin{array}{l}\text { Module } \\
\text { length, } \mathrm{mm}\end{array}$ & $\begin{array}{l}\mathrm{DK}_{\mathrm{UF}} \\
\mathrm{mL} / \mathrm{h} / \mathrm{mm} \mathrm{Hg}\end{array}$ & $\begin{array}{l}\text { Surface } \\
\text { area, } \mathrm{m}^{2}\end{array}$ & $\begin{array}{l}\text { Priming } \\
\text { volume, } \mathrm{mL}\end{array}$ \\
\hline Theranova 400 & 180 & 236 & 12,960 & 260 & 48 & 1.7 & 91 \\
\hline
\end{tabular}

is limited [2]. Increased concentration of medium-high molecular weight (MW) solutes has been correlated with negative clinical outcomes in CKD and in maintenance hemodialysis (HD) $[3,4]$. Attempts have been made to increase the spectrum and quantity of toxin removal by high flux dialysis (HFD) [5] or hemodiafiltration (HDF) $[6,7]$, but clinical outcomes are still suboptimal with unacceptable levels of complications [8-10]. A significant correlation between uremia-retention molecules and specific clinical problems has been demonstrated, such as dialysis-related amyloidosis ( $\beta-2$ microglobulin) [4] and malnutrition (inflammatory mediators, leptin and appetite-suppressing toxins) $[8,10,11]$. Cardiovascular complications and osteodystrophy are related to high levels of parathyroid hormone, homocysteine, and inflammatory cytokines [9]. Anemia has been correlated with specific erythropoiesis inhibitors and high levels of hepcidin [12$15]$. Polyclonal free light chains (k-FLC and $\lambda$-FLC) progressively accumulate in CKD and ESKD, increasing inflammation and accelerating atherosclerosis [11, 16-18]. Thus, new HD techniques with improved removal capabilities are highly desired.

Recent evolution in HD technology led to the development of a new class of membranes, defined as Medium cut-off (MCO) [19]. MCO membranes are characterized by high MW retention onset and MW cut-off value limiting albumin leak [20, 21]. Their introduction in clinical practice has made it possible to perform a new therapy called expanded HD (HDx) with increased removal capability in a wide spectrum of MWs [22]. This is due to higher permeability of the MCO membrane compared to classic high-flux membranes and an increased convective transport due to a remarkable amount of internal filtration (IF). IF guarantees high convective rates without requiring complex set up or fluid reinfusion (as in the case of HDF), since it is compensated by an adequate amount of backfiltration (BF) in the distal part of the hemodialyzer.

Large molecules have low diffusion coefficients and their removal requires the contribution of convection [23]. In HDF, convection rates are maximized but require a complex setup to maintain fluid balance through reinfusion [6]. In HDx, a similar amount of convective clearance is achieved by IF masked by BF in the distal part of the hemodialyzer [24]. Solute removal is optimized by the combination of the sieving properties of MCO membranes and the enhanced IF-BF mechanism due to a reduced inner diameter of hollow fibers [22]. Using a simple ultrafiltration-controlled HD modality, solute clearances in the spectrum of MWs traditionally retained with other techniques and membranes appear enhanced [25].

IF and BF in hollow fiber hemodialyzers have been previously estimated by different theoretical models [2628]; however, a direct quantification requires a complex experimental setting [29]. Empirical methods to directly quantify IF and BF have been proposed and validated in previous studies [30-33], but they have never been applied to MCO membranes. Given the importance of the hypothesized mechanism involved in HDx, it appears quintessential to empirically quantify the IF-BF phenomenon in a precise experimental setting reproducing classic in vivo operational conditions. The present study aims at quantifying IF and BF in $2 \mathrm{MCO}$ hemodialyzers using a nuclear imaging technique previously validated [30]. The obtained values may then be utilized for prescription of operational parameters in single patients undergoing HDx.

\section{Methods}

Two MCO hemodialyzers (Theranova 400 and 500, Baxter International Inc., Deerfield, IL, USA; Table 1) were studied in vitro in condition of zero net ultrafiltration $(\mathrm{IF}=\mathrm{BF})$ at blood flows $\left(\mathrm{Q}_{\mathrm{B}}\right)$ of 300 and $400 \mathrm{~mL} / \mathrm{min}$ and dialysate flow $\left(\mathrm{Q}_{\mathrm{D}}\right)$ of $500 \mathrm{~mL} / \mathrm{min}$. A non-diffusible marker molecule (albumin macro-aggregates) labeled with ${ }^{99} \mathrm{Tc}$ metastable was used to evaluate local cross filtration at different points along the length of the filter according to a previously validated method [30-32]. The in vitro test was carried out in a special room of the nuclear medicine department under strict protection policy.

The experimental setup consisted of a volume-controlled, counter-current blood and dialysate in vitro circuit (Figure 1). Blood obtained from human healthy volunteers $(1 \mathrm{bag}=600 \mathrm{~mL}$, hematocrit $\mathrm{Hct}=36 \%$, protein concentration $\mathrm{Cp}=5.9 \mathrm{~g} / \mathrm{dL})$ and 
Fig. 1. Schematic representation of the in vitro circuit. The layout demonstrates a complete sealing of the lines and no change in total volume is possible in either blood or dialysate compartment. The point of radioactive marker injection and the 4 sites for pressure measurement are indicated. The hemodialyzer and short segments of blood and dialysate lines are included in the image recording area.

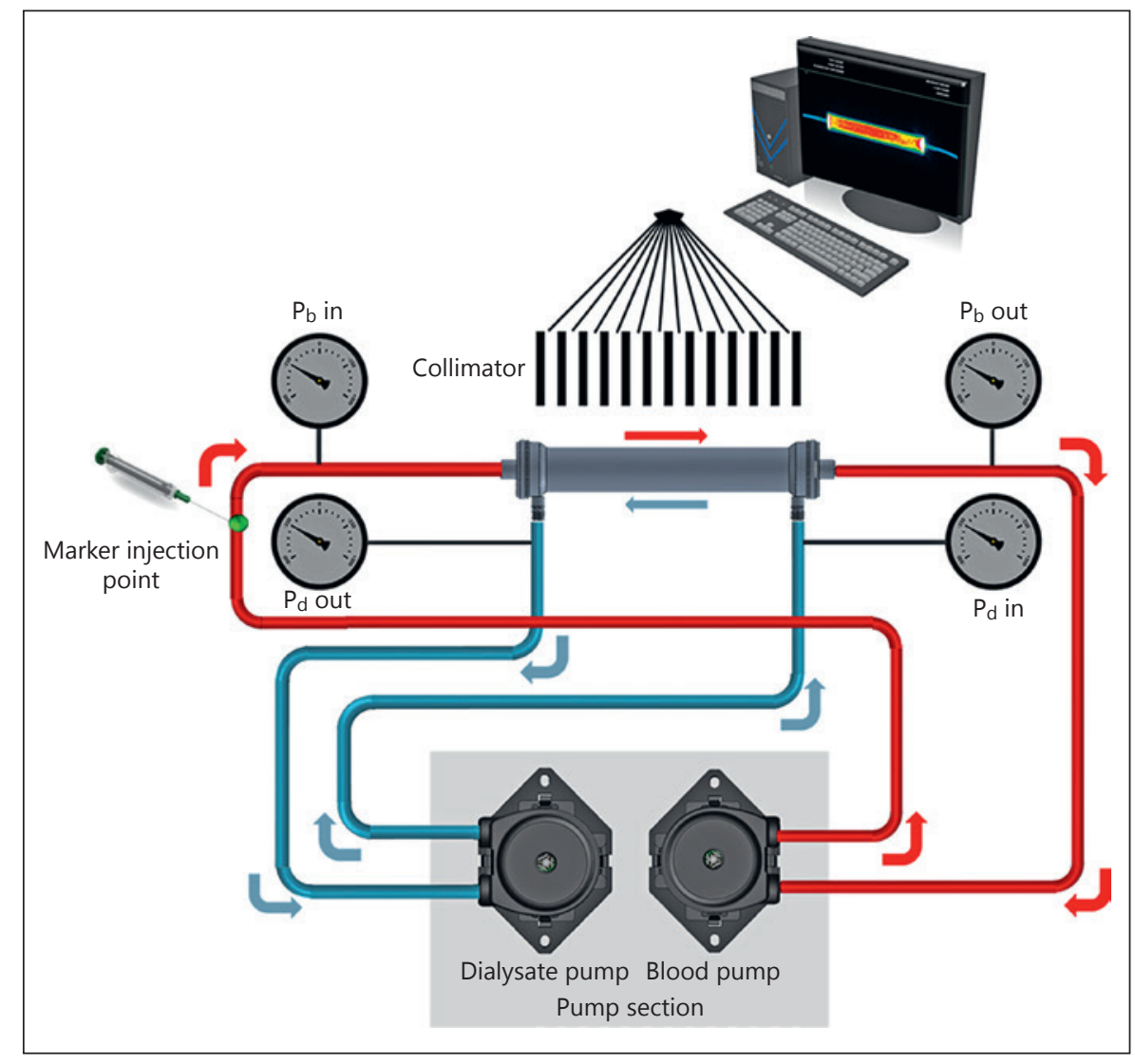

bicarbonate dialysate solution $\left(1 \mathrm{bag}=5,000 \mathrm{~mL}\right.$, Prismasol ${ }^{\circledR}$, Bax- $^{-}$ ter International Inc., Deerfield, IL, USA) thermostated at $37^{\circ} \mathrm{C}$ were used. Blood and dialysate were recirculated in a closed loop configuration ensuring zero net ultrafiltration $\left(\mathrm{Q}_{\mathrm{B}}=300\right.$ and $400 \mathrm{~mL} / \mathrm{min} ; \mathrm{Q}_{\mathrm{D}}=500 \mathrm{~mL} / \mathrm{min}$; net ultrafiltration rate $=0 \mathrm{~mL} /$ $\mathrm{min})$. In this condition, IF is by definition equal to BF. Four precision air manometers were connected at inlet and outlet ports of the hemodialyzer to record pressure values.

Once steady state was reached for every experimental condition, a non-diffusible labeled marker molecule was infused into the blood compartment of the circuit. A ${ }^{99 \mathrm{~m}}$ Technetium labeled human serum albumin macroaggregates kit that is commercially available (Macrotec, GE Healthcare, Milano, Italy) was used. The vial of the pharmaceutical contains $2 \mathrm{mg}$ of albumin macroaggregates, corresponding to $4.5 \times 106 \pm 15 \%$ particles with molecular diameter between 10 and $100 \mu \mathrm{m}$ (no particles greater than $150 \mu \mathrm{m}$ were present according to the manufacturer specifications).

Labeling with Sodium Pertechnetate ( ${ }^{99 \mathrm{~m} T c}$ ) Ph. Eur., freshly eluted from commercial ${ }^{99} \mathrm{Mo} /{ }^{99 \mathrm{~m}} \mathrm{Tc}$ generator, was performed according to manufacturer instructions and the amount of unbound radioactive ${ }^{99 \mathrm{~m}} \mathrm{Tc}$ was determined both by the non-filterable radioactivity method and by paper chromatography at $5 \mathrm{~min}$ and $4 \mathrm{~h}$ after labeling. Less than $1 \%$ of the total radioactivity was due to unbound ${ }^{99 \mathrm{~m}} \mathrm{Tc}$ resulting in a radiochemical purity greater than $99 \%$ over the time of the experiment. For each filter, a total activity of $185 \mathrm{MBq}$ in about $1.1 \mathrm{~mL}$ was used in a single injection. The average number of particles per preparation unit was estimated to be $1,125,000-1,350,000$ and the total activity was maintained con- stant over the time of the experiments. The images of the study were acquired with a hybrid Discovery $670 \mathrm{NM}$ /CT system manufactured by General Electric Medical System (Milwaukee, WI, USA) whose nuclear medicine component is equipped with a dual head gamma-camera. For the purposes of this study, only one head equipped with a high-resolution parallel hole collimator was used, while the second head and the CT component were disabled. The enable head was rotated upward and covered with a layer of transparent waterproof material to avoid contamination. The filter was securely taped to the collimator of the gamma-camera head, taking particular care to maintain the alignment of the body of the hemodialyzer with the main field of view axis, as indicated by the reference grid on the collimator. For each experimental setting, the tracer was injected in the blood line upstream the inlet of the hemodialyzer keeping the bolus compact.

A dynamic imaging sequence (30 frames of $2 \mathrm{~s}$, matrix $128 \times$ 128) was acquired immediately after the injection of the tracer and stored on a dedicated workstation for further evaluation. In order to ensure the achievement of the steady state condition, data acquisition started $5 \mathrm{~min}$ after bolus injection (when the radioactivity was uniformly distributed in the blood volume) and performed on a $256 \times 256,16$ byte matrix, with an electronic zoom factor of 1.33. Calculated pixel size was $1.66 \mathrm{~mm}$. Time, not counts, was chosen as a stop-code parameter in order to correct for different hemodialyzer models: acquisition time was 300 s per image. Acquired data were stored on a dedicated workstation (Xeleris release 3 , GEMS) and preliminarily evaluated onsite to confirm the good quality of each study. 
Table 2. Hemodynamic parameters and results in different experimental conditions

\begin{tabular}{|c|c|c|c|c|}
\hline \multirow[b]{2}{*}{ Blood flow, mL/min } & \multicolumn{2}{|c|}{ Theranova 400} & \multicolumn{2}{|c|}{ Theranova 500} \\
\hline & 300 & 400 & 300 & 400 \\
\hline Dialysate flow, $\mathrm{mL} / \mathrm{min}$ & 500 & 500 & 500 & 500 \\
\hline Plasma fow, $\mathrm{mL} / \mathrm{min}$ & 192 & 256 & 192 & 256 \\
\hline Blood inlet pressure, $\mathrm{mm} \mathrm{Hg}$ & 190 & 215 & 180 & 205 \\
\hline Blood outet pressure, $\mathrm{mm} \mathrm{Hg}$ & 65 & 50 & 65 & 50 \\
\hline Dialysate outlet pressure, $\mathrm{mm} \mathrm{Hg}$ & 85 & 85 & 70 & 80 \\
\hline Oncotic intlet pressure, $\mathrm{mm} \mathrm{Hg}$ & 20 & 20 & 20 & 20 \\
\hline Oncotic outlet pressure, $\mathrm{mm} \mathrm{Hg}$ & 20 & 20 & 20 & 20 \\
\hline Transmembrane inlet pressure, $\mathrm{mm} \mathrm{Hg}$ & 85 & 110 & 90 & 105 \\
\hline Transmembrane outlet pressure, $\mathrm{mm} \mathrm{Hg}$ & -80 & -95 & -70 & -90 \\
\hline Marker molecule inlet count $\mathrm{C}_{\mathrm{i}}$ & 5,787 & 6,800 & 5,737 & 6,345 \\
\hline Backfiltration BF, mL/min & 29.31 & 40.58 & 31.11 & 52.30 \\
\hline
\end{tabular}

The marker molecule concentrations were recorded along the length of the hemodialyzers as counts. Since albumin macroaggregates do not cross the membrane because of their dimension, changes in their concentration along the hemodialyzer are due to local variations of water content in the blood compartment. Filtration flows can be locally and cumulatively derived accordingly. Increase in concentration of the marker molecule describes IF, while its decrease describes BF.

IF can be calculated as:

$$
\mathrm{IF}=\mathrm{Q}_{\mathrm{B}}(1-\mathrm{Hct}) \times\left(1-\mathrm{C}_{\text {in }} / \mathrm{C}_{\max }\right)
$$

where $\mathrm{Q}_{\mathrm{B}}$ is the blood flow rate, Hct is the hematocrit, $\mathrm{C}_{\text {in }}$ is the count of the marker molecule at the inlet of the dialyzer, and $\mathrm{C}_{\max }$ is the peak count of the marker molecule along the length of the dialyzer.

BF can be calculated as:

$$
\mathrm{BF}=\mathrm{Q}_{\mathrm{B}}(1-\mathrm{Hct}) \times\left(1-\mathrm{C}_{\text {out }} / \mathrm{C}_{\max }\right)
$$

where $\mathrm{C}_{\text {out }}$ is the count of the marker at the outlet of the hemodialyzer.

IF and $\mathrm{BF}$ are therefore calculated using plasma flow rate since the marker molecule is confined to the plasma volume space. Hct $_{\text {in }}$ and $\mathrm{Hct}_{\text {out }}$ were the same as $\mathrm{Q}_{\text {Bin }}$ and $\mathrm{Q}_{\text {Bout }}$.

At steady state, when $\mathrm{C}_{\text {in }}$ and $\mathrm{C}_{\text {out }}$ display equal values, $\mathrm{IF}=\mathrm{BF}$ equation demonstrates that the setting provided by the physical model of zero net filtration holds true.

$\mathrm{C}_{\text {in }}$ and $\mathrm{C}_{\text {out }}$ measurements are performed in the potting region of the fiber bundle where the cross section is uniform. In fact, cross filtration does not occur at the extremes of the hemodialyzer while the configuration of the blood ports may induce artifacts in the scintigraphic intensity that must be discarded. For this reason, only the effective length of the hemodialyzer was utilized for the calculation.

IF in MCO membrane
Moving average was applied to the acquired data in order to detect the peak value: the scope was to make the signal smooth and eliminate possible confounding effects.

\section{Results}

All safety measures were fully utilized during the experiment and no hazards resulted from the in vitro circuit and nuclear marker utilization. Prior to the marker molecule injection, a steady state circulatory condition was achieved in all experiments. The complete set of pressure values for blood and dialysate compartments of the 2 filters, at different $\mathrm{Q}_{\mathrm{B}}$ is reported in Table 2 .

In Figure 2, we report the dynamic imaging sequence in the 2 hemodialyzers immediately after the injection of the marker molecule in the inflow line. The dynamic sequences clearly display the bolus of macroaggregates entering the fiber bundle and progressing through the length of the hemodialyzer. The tridimensional analysis of the imaging sequence confirmed a homogeneous cross-sectional distribution of the bolus in the fiber bundle. Considering the $\mathrm{Q}_{\mathrm{B}}$ of $400 \mathrm{~mL} / \mathrm{min}$, the bolus transit time was 13.65 and $15.75 \mathrm{~s}$ for the 400 and 500 hemodialyzers. The images reflect the first (a) and second (b) passage of the bolus. A complete mixing of the blood with the marker molecule was achieved after 3 min as confirmed by the visual inspection and the images on the console, while images for cross filtration evaluation were acquired starting at $5 \mathrm{~min}$ after injection. 

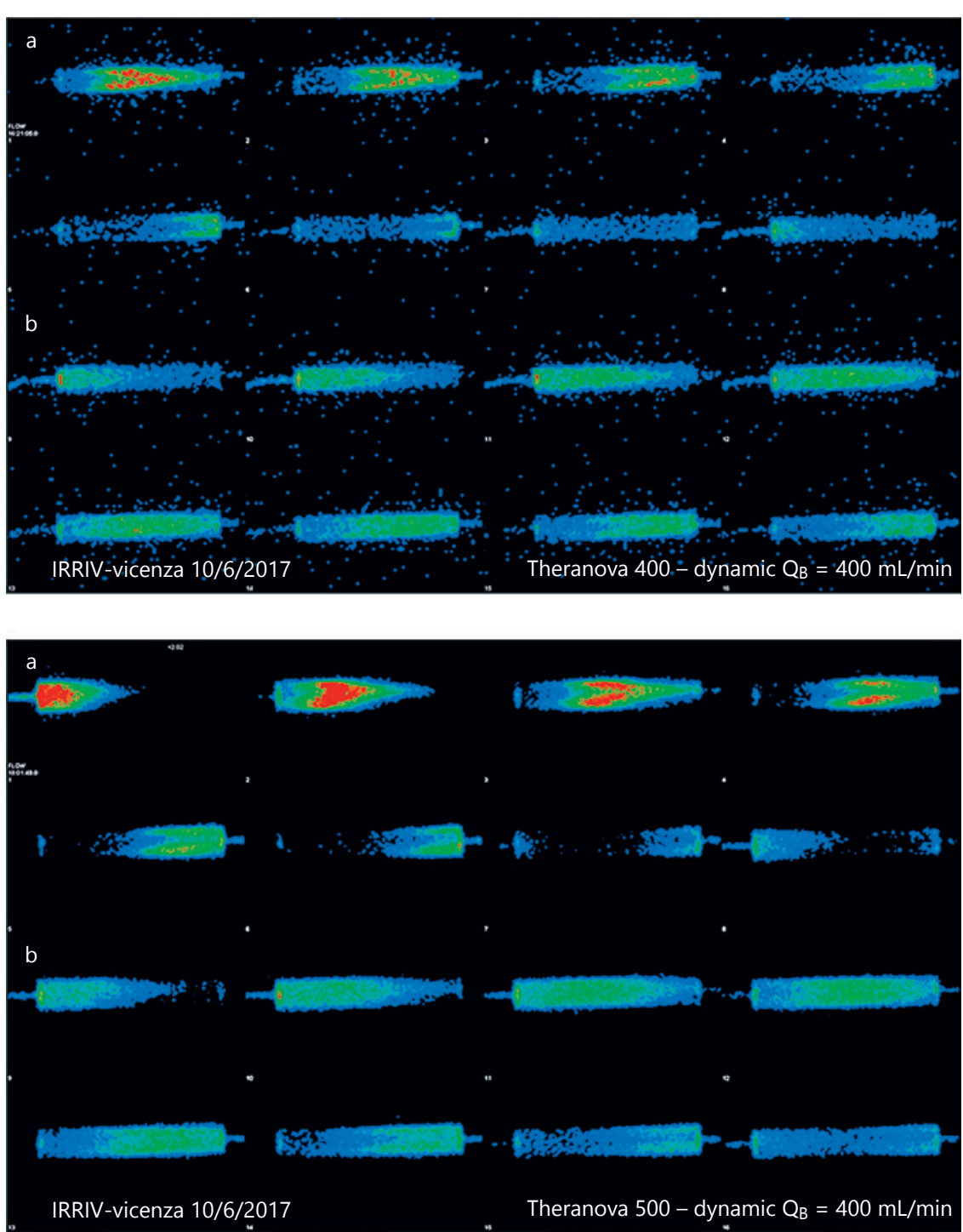

Fig. 2. Dynamic imaging sequence of Theranova 400 and Theranova 500 hemodialyzers at blood flow of $400 \mathrm{~mL} / \mathrm{min}$. Image sequences display the patterns of bolus distribution and progress along the fibers just after injection. In each panel, the first 2 rows describe first passage (a), while the second 2 rows describe second passage (b). In the second passage, the more homogeneous distribution of the marker molecule becomes evident.
Figure 3 reports the images of the 2 filters recorded by the console at steady state for the 2 blood flow conditions studied. The change in color corresponds to the relative variation of the radiolabeled marker molecule activity in a numerical scale. Radioactive counts are proportional to the marker molecule concentration in blood (graphs on the right part of the figure). The images obtained for the 2 filters can be compared in terms of relative changes but not in terms of absolute values of the marker molecule concentration, since the ratio between the initial marker dose infused at the beginning of the experiment and the total priming volume of the circuit were slightly different between hemodialyzers of different dimension.

As shown in Figure 3, artifacts due to radioactivity accumulation in the blood ports were ignored, since they refer to segments outside the effective length of the hemodialyzer (Table 1). For the calculation of segmental transmembrane crossflow, the effective length of fibers excluding the potting was considered. The experimental setting and the sealed dialysate/blood circuit guaranteed the condition of zero net filtration. This was further confirmed by very close values of the radioactivity and marker molecule concentration at the inlet and outlet of the fiber bundle. The absence of any radioactivity in the dialysate compartment confirmed the confinement of the non-diffusible marker molecule in the blood compartment only.

In the area of the hemodialyzer where membrane cross flow is possible, radioactivity counts display significant variations due to direct and reverse transmembrane water fluxes (Fig. 3). In the proximal part, radioactive counts 
Fig. 3. Steady state images of Theranova 400 and Theranova 500 at blood flow of 300 and $400 \mathrm{~mL} / \mathrm{min}$ are reported together with the count profile provided by the console. The amplitude of the marker molecule concentration variation from the inlet to the peak value is greater at the highest blood flows in both filters. Maximum increase from initial value is achieved at the highest blood flow in the hemodialyzer with the largest surface area (Theranova $500)$. The return of the curve to the initial count measured at the inlet of the hemodialyzer demonstrates that no net filtration was recorded by the method. This condition was hydraulically guaranteed and served as a quality control measure to ensure the accuracy of the method.
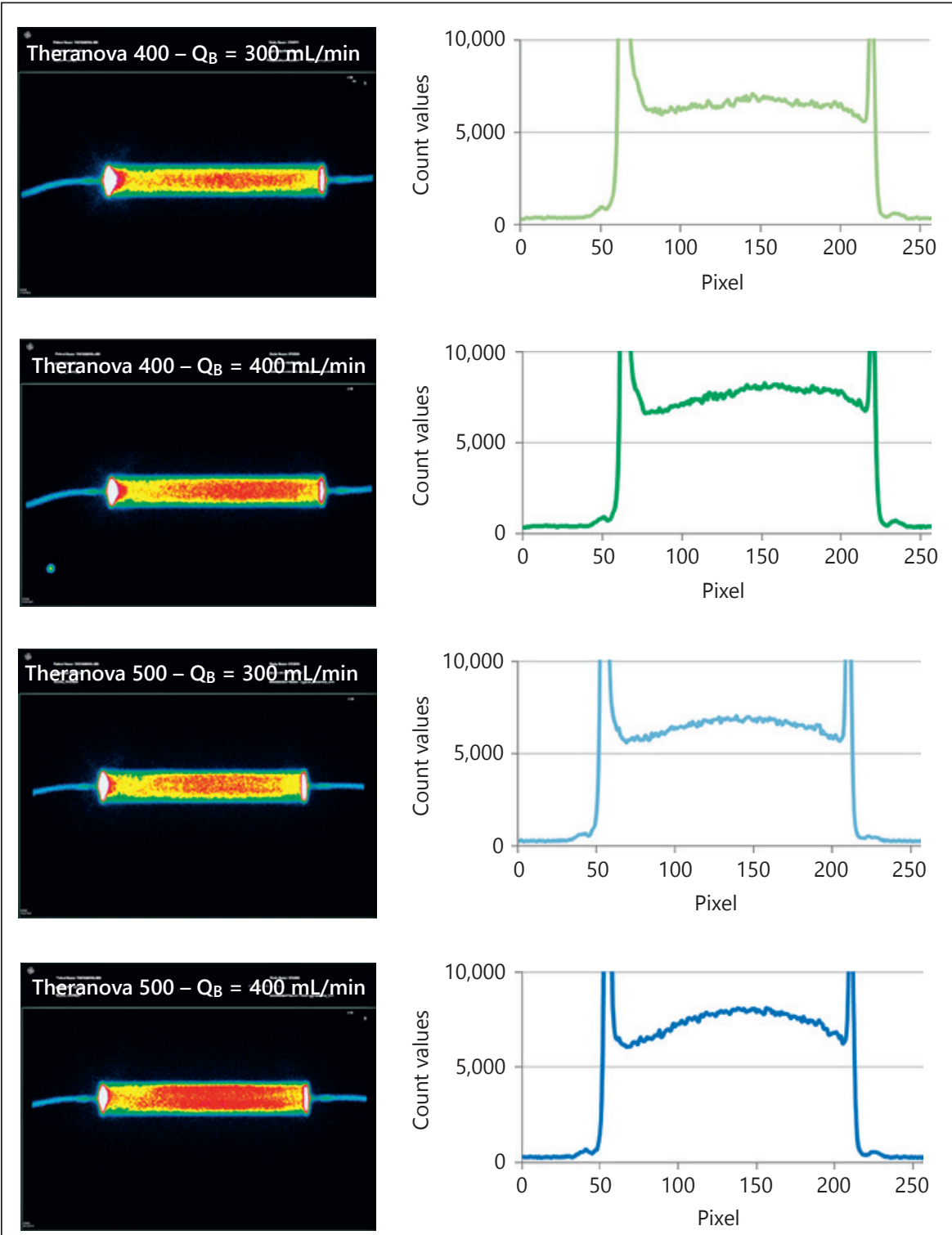

progressively increase reaching a peak concentration $\left(\mathrm{C}_{\max }\right)$ somewhere in the middle segment of the hemodialyzer that indicates an increase in the concentration of the marker molecule due to the direct filtration of plasma water from blood into dialysate. Then, a significant decrease of radioactive counts is observed in the distal part of the fiber bundle reaching at the outlet almost the same level as that of the inlet. This indicates a dilution of the marker molecule due to BF of dialysate into the blood. The variations in concentration of the marker molecule are due to the local transmembrane cross flow of plasma water through the membrane in both directions. For each filter, at higher $\mathrm{Q}_{\mathrm{B}}$, the peak concentration tends to move slightly toward the distal part of the hemodialyzer. For Theranova 400 , concentration peaked at $53.41 \%$ at $\mathrm{Q}_{\mathrm{B}}=$ $300 \mathrm{~mL} / \mathrm{min}$, while $56.25 \%$ at $400 \mathrm{~mL} / \mathrm{min}$. For Theranova 500 , the peak was at $55.68 \%$ of the fiber length for $\mathrm{Q}_{B}$ of $300 \mathrm{~mL} / \mathrm{min}$ vs. $58.52 \%$ at $400 \mathrm{~mL} / \mathrm{min}$.

IF calculated by the equations described in the Method section are reported in Table 2. For both filters, higher $\mathrm{Q}_{B}$ led to higher amounts of IF. For Theranova 400, IF was $29.69 \mathrm{~mL} / \mathrm{min}$ at a $\mathrm{Q}_{B}$ of $300 \mathrm{~mL} / \mathrm{min}$, while it was $41.62 \mathrm{~mL} / \mathrm{min}$ at a $Q_{B}$ of $400 \mathrm{~mL} / \mathrm{min}$. For Theranova 500 , IF were 31.57 and $53.11 \mathrm{~mL} / \mathrm{min}$ at $\mathrm{Q}_{B}$ of 300 and $400 \mathrm{~mL} /$ min respectively. IF proportionally increased with $\mathrm{Q}_{\mathrm{B}}$ and hemodialyzer surface area with a greater impact of $\mathrm{Q}_{\mathrm{B}}$. 


\section{Discussion}

In spite of remarkable technical and clinical improvements, long-term outcomes of patients undergoing chronic HD are still suboptimal with a high rate of hospitalization and mortality. Such results are partly due to the ever-changing case mix with a continuous increase of older and sicker population. Nevertheless, we may recognize important limitations of current dialysis technology that appears to be incapable of achieving adequate blood purification from several identified uremic toxins [1-6, 34-36]. Continuous innovation and research are therefore needed to improve quality of care and to find solutions for unmet clinical needs [37, 38].

The demonstration that specific complications are related to the accumulation of defined retention solutes, the awareness that current dialysis membranes are inadequate to achieve the desired clearances of such solutes, and the desire to improve ESKD patient outcomes have spurred remarkable interest in developing and testing newer dialysis membranes $[19,37]$.

The new MCO membrane is characterized by an innovative permeability profile [39]. This presents a high retention onset, that is, a sieving value of 0.9 for solutes with $\mathrm{MW}$ in the range of $11 \mathrm{KDa}$ and a cut-off value (where the sieving value is 0.1 ) for MW close but lower than that of albumin. This innovative profile has been reported to guarantee an excellent clearance of mediumlarge MW solutes compared to standard high-flux membranes while preventing significant losses of albumin as in the case of high cut-off membranes [20,22,38].

High-flux membranes are applied in HFD or HDF where convection represents an important transport mechanism in addition to diffusion, to improve the removal of medium-large MW solutes. In HDF, convective transport is obtained by high ultrafiltration rates, exceeding the amount of fluid removal required by the patient [40]. Desired fluid balance is obtained by the reinfusion of commercial or online prepared solutions. In HFD, convection is achieved inside the dialyzer by a mechanism of IF, which is masked by a relative amount of BF so that no reinfusion is needed, while net ultrafiltration and patient weight loss are governed by the equipment [24].

IF cannot be measured directly during dialysis and it must be estimated based on theoretical or experimental models. In previous studies, we evaluated several hollow fiber hemodialyzers with high-flux membranes of different surface areas [26, 28-31]. For a surface area of $1.8 \mathrm{~m}^{2}$ (equivalent to Theranova 400), we directly measured a value of IF in the range of $20-25 \mathrm{~mL} / \mathrm{min}$ at $\mathrm{Q}_{\mathrm{B}}$ between
250 and $350 \mathrm{~mL} / \mathrm{min}$. IF values increased per $\mathrm{m}^{2}$ in case of experimental hemodialyzers with membranes of higher hydraulic permeability, modified hemodialyzer design, or reduced inner diameter of hollow fibers [31]. These values were slightly overestimated by the use of blood flow instead of plasma flow. The Theranova hemodialyzers studied in our experiments combine some of those characteristics with the intent to increase IF, so we would expect much higher values. In particular, the reduced inner diameter of the fibers in conjunction with the hydraulic permeability of the membrane and the shape of the hemodialyzer suggest that IF should be enhanced. We originally conducted a theoretical analysis on Theranova hemodialyzers based on reported technical data and we developed different mathematical models to estimate IF [41]. The results of the experimental scintigraphic analysis confirmed the values of IF previously estimated by the mathematical method recently published [41] for both hemodialyzers at $\mathrm{Q}_{\mathrm{B}}$ of $300 \mathrm{~mL} / \mathrm{min}$. In particular, the mathematical method and the scintigraphic one differ by $2.01 \mathrm{~mL} / \mathrm{min}(27.68$ vs. $29.69 \mathrm{~mL} / \mathrm{min})$ and by $0.51 \mathrm{~mL} /$ $\min (31.06$ vs. $31.57 \mathrm{~mL} / \mathrm{min}$ ) for Theranova 400 and Theranova 500 respectively. On the contrary, the mathematical model underestimates the IF at $400 \mathrm{~mL} / \mathrm{min}$ of $\mathrm{Q}_{\mathrm{B}}$ in comparison with the scintigraphic method: for Theranova 400, the difference is $9.77 \mathrm{~mL} / \mathrm{min}$ (31.85 vs. $41.62 \mathrm{~mL} / \mathrm{min}$ ), while for Theranova 500 , the difference is $20.14 \mathrm{~mL} / \mathrm{min}(32.97$ vs. $53.11 \mathrm{~mL} / \mathrm{min})$. Therefore, while the mathematical model displays a remarkable accuracy at $\mathrm{Q}_{\mathrm{B}}$ of $300 \mathrm{~mL} / \mathrm{min}$, a correction factor should be introduced in the estimation equation when higher blood flows are utilized.

Regardless of minimal differences between the mathematical estimation and the direct experimental measurement, the IF values of Theranova hemodialyzers appear significantly higher than those of any other hemodialyzer previously studied.

The combination of the MCO membrane sieving profile and the high IF rates permits the possibility to perform a new form of therapy-defined HDx [22]. This extracorporeal technique has the potential to remove medium-large MW solutes with greater efficiency compared to other forms of treatments. In the presence of increased sieving values for molecules such as $\beta-2$ microglobulin or FLC, high clearances are achieved by an optimal product between filtration rates and sieving values [17]. The fiber length and inner diameter are essential elements to optimize the mechanism of IF/BF. This mechanism, although invisible, makes it possible to achieve significant amount of convection inside the dialyzer where filtration takes 
place in the proximal part and BF compensates in the distal part. The ultrafiltration control system of the dialysis machine regulates the process and provides the exact amount of net filtration required for the scheduled weight loss of the patient. Initial reports of clinical application of MCO membrane and HDx therapy demonstrated encouraging results and are now under evaluation in larger and articulated clinical trials. Our study offers the possibility to understand the mechanism on the basis of $\mathrm{HDx}$ therapy and enables clinicians to quantify the convective transport occurring internally in the hemodialyzers. In the future, this parameter may become useful to personal- ize treatment prescription and to propose individual parameters in the setting of the dialysis equipment. Last but not least, the IF/BF mechanism does not require complicated fluid balance calculation or complex equipment but can be performed like any other ultrafiltration-controlled dialysis technique.

\section{Disclosure Statement}

The authors declare that they have no conflicts of interests to disclose.

\section{References}

1 Vanholder R, De Smet R, Glorieux G, Argiles A, Baurmeister U, Brunet P, Clark W, Cohen G, De Deyn PP, Deppisch R, Descamps-Latscha B, Henle T, Jorres A, Lemke HD, Massy ZA, Passlick-Deetjen J, Rodriguez M, Stegmayr B, Stenvinkel P, Tetta C, Wanner C, Zidek W: Review on uremic toxins: classification, concentration, and interindividual variability. Kidney Int 2003;63:1934-1943.

2 Neirynck N, Vanholder R, Schepers E, Eloot S, Pletinck A, Glorieux G: An update on uremic toxins. Int Urol Nephrol 2013;45:139150.

3 Miyata T, Jadoul M, Kurokawa K, Van Ypersele de Strihou C: Beta-2 microglobulin in renal disease. J Am Soc Nephrol 1998;9:17231735.

4 Cianciolo G, Coli L, La Manna G, Donati G, D'Addio F, Comai G, Ricci D, Dormi A, Wratten M, Feliciangeli G, Stefoni S: Is beta2microglobulin-related amyloidosis of hemodialysis patients a multifactorial disease? A new pathogenetic approach. Int J Artif organs 2007;30:864-878.

5 Ronco C, Brendolan A, Bragantini L, Chiaramonte S, Fabris A, Feriani M, Dell'Aquila R, Milan M, Scabardi M, Pinna V, et al: Technical and clinical evaluation of different short, highly efficient dialysis techniques. Contrib Nephrol 1988;61:46-68.

6 Ronco C: Hemodiafiltration: evolution of a technique towards better dialysis care. Contrib Nephrol 2011;168:19-27.

7 Ronco C: Hemodiafiltration: technical and clinical issues. Blood Purif 2015;40(suppl 1): 2-11.

8 Dai L, Golembiewska E, Lindholm B, Stenvinkel P: End-stage renal disease, inflammation and cardiovascular outcomes. Contrib Nephrol 2017;191:32-43.

9 Cozzolino M, Galassi A, Pivari F, Ciceri P, Conte F: The cardiovascular burden in endstage renal disease. Contrib Nephrol 2017; 191:44-57.

10 Jankowska M, Cobo G, Lindholm B, Stenvinkel P: Inflammation and protein-energy wast- ing in the uremic milieu. Contrib Nephrol 2017;191:58-71.

11 Desjardins L, Liabeuf S, Lenglet A, Lemke HD, Vanholder R, Choukroun G, Massy ZA: Association between free light chain levels, and disease progression and mortality in chronic kidney disease. Toxins 2013;5:20582073.

12 Ueda N, Takasawa K: Role of hepcidin-25 in chronic kidney disease: anemia and beyond. Curr Med Chem 2017;24:1417-1452.

13 Ashby D, Busbridge M, Hildebrand S, Clarke C, Aldous G, Palan M, Murphy K, Duncan N, Choi P: Hepcidin clearance is associated with erythropoietin requirement in stable hemodialysis patients. Clin Nephrol 2017;87:231236.

14 Madu AJ, Ughasoro MD: Anaemia of chronic disease: an in-depth review. Med Princ Prac 2017;26:1-9.

15 Deicher R, Horl WH: Hormonal adjuvants for the treatment of renal anaemia. Eur J Clin Invest 2005;35(suppl 3):75-84.

16 Qian Q: Inflammation: a key contributor to the genesis and progression of chronic kidney disease. Contrib Nephrol 2017;191:72-83.

17 Boschetti-de-Fierro A, Beck W, Hildwein H, Krause B, Storr M, Zweigart C: Membrane innovation in dialysis. Contrib Nephrol 2017; 191:100-114.

18 Burmeister A, Assi LK, Ferro CJ, Hughes RG, Barnett AH, Bellary S, Cockwell P, Pratt G, Hutchison CA: The relationship between high-sensitivity CRP and polyclonal free light chains as markers of inflammation in chronic disease. Int J Lab Hematol 2014;36:415-424.

19 Ronco C, Clark WR: Membranes for hemodialysis. Nat Rev Nephrol 2018, in press.

20 Boschetti-de-Fierro A, Voigt M, Storr M, Krause B: Extended characterization of a new class of membranes for blood purification: the high cut-off membranes. Int J Artif Organs 2013;36:455-463.

21 Boschetti-de-Fierro A, Voigt M, Storr M, Krause B: MCO membranes: enhanced selectivity in high-flux class. Sci Rep 2015;5:18448.
22 Ronco C: The rise of expanded hemodialysis. Blood Purif 2017;44:I-VIII.

23 LocatelliF, Gauly A, CzekalskiS, Hannedouche T, Jacobson SH, Loureiro A, Martin-Malo A, Papadimitriou M, Passlick-Deetjen J, Ronco C, Vanholder R, Wizemann V: The MPO study: just a european HEMO study or something very different? Blood Purif 2008;26: 100-104.

24 Clark WR, Gao D, Neri M, Ronco C: Solute transport in hemodialysis: advances and limitations of current membrane technology. Contrib Nephrol 2017;191:84-99.

25 Kirsch AH, Rosenkranz AR, Lyko R, Krieter $\mathrm{DH}$ : Effects of hemodialysis therapy using dialyzers with medium cut-off membranes on middle molecules. Contrib Nephrol 2017;191: 158-167.

26 Fiore GB, Guadagni G, Lupi A, Ricci Z, Ronco C: A new semiempirical mathematical model for prediction of internal filtration in hollow fiber hemodialyzers. Blood Purif 2006;24: 555-568.

27 Lee JC, Lee K, Kim HC: Mathematical analysis for internal filtration of convection-enhanced high-flux hemodialyzer. Comput Methods Programs Biomed 2012;108:68-79.

28 Fiore GB, Ronco C: Principles and practice of internal hemodiafiltration. Contrib Nephrol 2007;158:177-184.

29 Ronco C: Fluid mechanics and crossfiltration in hollow-fiber hemodialyzers. Contrib Nephrol 2007;158:34-49.

30 Ronco C, Brendolan A, Feriani M, Milan M, Conz P, Lupi A, Berto P, Bettini M, La Greca G: A new scintigraphic method to characterize ultrafiltration in hollow fiber dialyzers. Kidney Int 1992;41:1383-1393.

31 Ronco C, Brendolan A, Lupi A, Metry G, Levin NW: Effects of a reduced inner diameter of hollow fibers in hemodialyzers. Kidney Int 2000;58:809-817.

32 Rangel AV, Kim JC, Kaushik M, Garzotto F, Neri M, Cruz DN, Ronco C: Backfiltration: past, present and future. Contrib Nephrol 2011;175:35-45. 
33 Ronco C, Orlandini G, Brendolan A, Lupi A, La Greca G: Enhancement of convective transport by internal filtration in a modified experimental hemodialyzer: technical note. Kidney Int 1998;54:979-985.

$34 \mathrm{Yu} \mathrm{X:} \mathrm{The} \mathrm{evolving} \mathrm{patterns} \mathrm{of} \mathrm{uremia:} \mathrm{Un-}$ met clinical needs in dialysis. Contrib Nephrol 2017;191:1-7.

35 Massy ZA, Liabeuf S: Middle-molecule uremic toxins and outcomes in chronic kidney disease. Contrib Nephrol 2017;191: 8-17.

36 Barreto FC, Barreto DV, Canziani MEF: Uremia retention molecules and clinical outcomes. Contrib Nephrol 2017;191:1831.

37 Ronco C, Crepaldi C, Brendolan A, Bragantini L, d'Intini V, Inguaggiato P, Bonello M, Krause B, Deppisch R, Goehl H, Scabardi A: Evolution of synthetic membranes for blood purification: the case of the polyflux family. Nephrol Dial Transplant 2003;18(suppl 7):vii10-vii20.

38 Ward RA: Protein-leaking membranes for hemodialysis: a new class of membranes in search of an application? J Am Soc Nephrol 2005; 16:2421-2430.

39 Ronco C, Neri M, Lorenzin A, Garzotto F, Clark WR: Multidimensional classification of dialysis membranes. Contrib Nephrol 2017; 191:115-126.

40 Maduell F, Moreso F, Pons M, Ramos R, Mora-Macia J, Carreras J, Soler J, Torres F, Campistol JM, Martinez-Castelao A: Highefficiency postdilution online hemodiafiltration reduces all-cause mortality in hemodialysis patients. J Am Soc Nephrol 2013;24:487497

41 Lorenzin A, Neri M, Clark WR, Garzotto F, Brendolan A, Nalesso F, Marchionna N, Zanella M, Sartori M, Fiore GB, Ronco C: Modeling of internal filtration in theranova hemodialyzers. Contrib Nephrol 2017;191:127-141. 